\title{
Module Partition Methodology of Heavy Duty Machine Tools for Green Remanufacturing
}

\author{
Ligang Cai ${ }^{1, a)}$, Weishuo $\mathrm{Li}^{1, \mathrm{~b})}$, Qiang Cheng ${ }^{1, \mathrm{c})}$, Guangpeng $\mathrm{Li}^{1, \mathrm{~d})}$, Bingwei \\ Sun ${ }^{1, e)}$ \\ ${ }^{1}$ College of Mechanical Engineering and Applied Electronics Technology, \\ Beijing University of Technology, Beijing 100124, China. \\ a'Lgcai321@aliyun.com, b1522933615@qq.com, 'chengqiang@bjut.edu.cn, \\ d1030864713@qq.com, ${ }^{\mathrm{e}} 1359750743 @ q q . c o m$
}

Keywords: Module Partition, Heavy Duty Machine Tools, Green Remanufacturing.

\begin{abstract}
In this paper, in order to improve the green remanufacturing capacity of heavy duty machine tools, the design domain of axiomatic design is taken as the main line and extended it to the regeneration domain innovatively. The design structure matrix is used to consider the correlation and similarity of design parameters between structural domain and regeneration domain. The particle swarm optimization algorithm based on the minimal description length is used to find the ideal modular design method for heavy machine tools.
\end{abstract}

\section{INTRODUCTION}

Machine tools is an important strategic material of the country, is the symbol of the equipment manufacturing industry. Because of the high quality, high materials consumption, high energy consumption and high cost, the waste products scrapped directly will lead to a huge waste of resources and energy. Therefore, it is an important problem to solve the problem of how to realize the green remanufacturing, to make the old machine tools rejuvenate the vitality and extend the service cycle. In recent years, a more conform to the requirements of sustainable development of waste disposal method - green remanufacturing has attracted wide attention of the whole society [1]. Green remanufacturing can prolong the service cycle through disassembly, repair, replacement and upgrade of the parts, so that the old heavy machine tools to radiate new vitality. At present, the domestic and foreign researchers have done a lot of work in the field of machine tools remanufacturing and machine tools module partition. Cao pointed out that in the fierce market competition, remanufacturing machine tools should be oriented to the different customer requirements, from the customer requirements to establish the design framework and model [2]. Du proposed a method to evaluate the reproducibility of waste machine tools, and analyzed the technical feasibility, economic feasibility and environmental benefits of remanufacturing machine tools [3]. Liu et al. established from the aspects of materials selection, remanufacturing process performance, use and maintenance performance, economic efficiency, and functional and physical feasibility for modular design of machine tools for remanufacturing combined with the characteristics of the various stages of product life cycle, disassembly criteria [4]. Sheng et al. introduced lifecycle-oriented modular design idea, Lifecycle-oriented CNC machine tools modular design method pays more attention to environmental attributes of the product, and considers the consciousness of environmental protection and sustainability in product design well [5]. However, in order to improve the adaptability and remanufacturing capability of machine tools, the criterion of module partition is not only related to the functional integrity and structural rationality, but also needs to predict potential user regeneration requirements in advance, consider the differences in manufacturing resources and remanufacturing technological process. How to consider in advance the difficulties and bottlenecks of regenerative manufacturing in the design stage, and improve the ability of green manufacturing, there are still many contents to be further studied.

This paper proposes a module partition methodology of heavy duty machine tools for green 
remanufacturing, in order to improve the regeneration of machine tools and reduce the manufacturing cost of machine tools, thus prolonging the service cycle, improving the competitiveness of enterprises, reducing the consumption of resources.

\section{RESEARCH THINKING AND FRAMEWORK}

\section{Research framework}

In order to improve the green remanufacturing capability of heavy machine tools, this paper predicts and considers the difficulties and bottlenecks of remanufacturing in the design stage, and explores the module design method of heavy duty machine tool with green design concept. The research framework is shown in figure 1. This study takes four design domains of axiomatic design (AD) as the main line, and extend them to the regeneration domain innovatively [6]. The design structure matrix (DSM) is used to consider clearly and intuitively the correlation and similarity of design parameters between structural domain and regeneration domain [7]. The particle swarm optimization (PSO) algorithm based on the minimal description length (MDL) is used to find the ideal modular design method for heavy machine tools $[8,9]$.

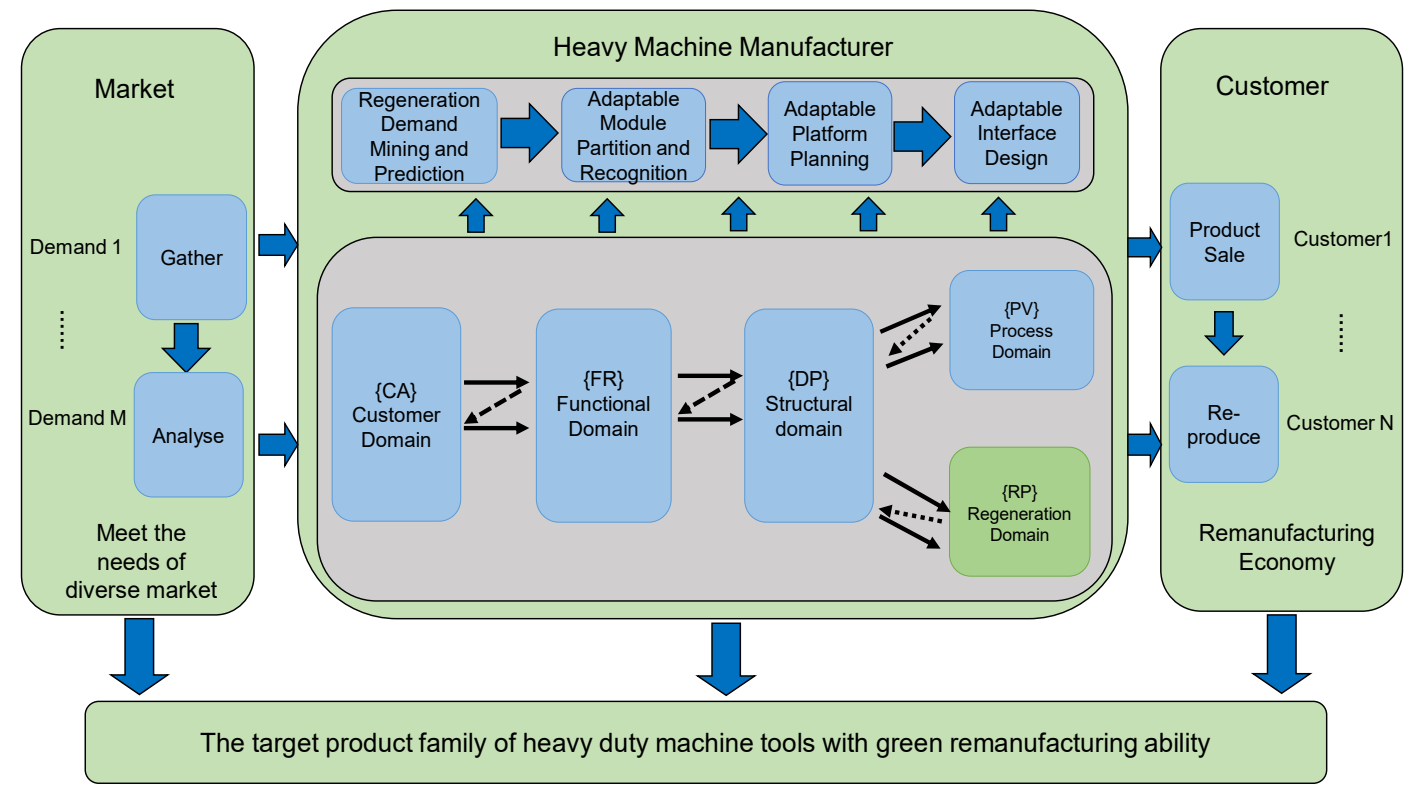

FIGURE 1. Research framework.

\section{Modular partition principle of heavy machine tools for remanufacturing}

The method partition method of heavy-duty machine tools for remanufacturing takes DSM as the main analysis tool. The implementation framework is divided into five steps: (1) The establishment of design parameters correlation DSM for regeneration; (2) The establishment of design parameters correlation DSM for structure; (3) The establishment of design parameters similarity DSM for remanufacturing process; (4) Module partition based on PSO-MDL algorithm.

The hierarchical mapping between design domains provides a guarantee for module partitioning in $\mathrm{AD}$. The method proposed in this paper is mainly analyzed from structural domain and regeneration domain of heavy machine tools. First, the design matrix between design domains of heavy machine tools is established based on $\mathrm{AD}$ and divided and quantified by analytic hierarchy process (AHP) [10], and then the design matrix is transformed into DSM which is considered from the regeneration angle by the total differential method. In structural domain itself, the interaction relationship between the design parameters is analyzed from the physical and geometric angles, and design parameters correlation DSM for structure is established. In the third step, in order to improve the remanufacturing process and production efficiency of modular heavy machine tools, a similarity DSM of design parameters is established based on the similarity principle for the heavy machine tool remanufacturing process. So far, the interaction relation matrix of design parameters which is expressed by DSM from two aspects of structure and regeneration has been obtained, which 
provides a basis a for the reasonable module partition. Finally, the PSO algorithm based on MDL is used to analyze the obtained DSM and realize the module partition of heavy machine tools.

\section{THE ESTABLISHMENT OF DESIGN PARAMETERS CORRELATION DSM OF HEAVY MACHINE TOOLS}

In the modular design of heavy duty machine tool for remanufacturing, the rationality of module partition is the foundation and key to implement modular design. In order to properly describe the interaction value between the design parameters of heavy machine tools, the module partition should focus on the correlation of heavy machine tools in the structure and the regeneration process, and the mapping relation between structural domain and regeneration domain in $\mathrm{AD}$ method provides a good framework for modular design. Therefore, the modularity needs to be mapped onto structure of heavy machine tools ultimately. In the following, the correlation DSM of design parameters of the structural domain are constructed based on AD from the viewpoint of structure and regeneration, respectively.

\section{The DSM of design parameters correlation for regeneration}

The relationship between design parameters and remanufacturing process variables of heavy machine tools can be written as follows

$$
D P=[A] R P
$$

Where $[A]$ represents the design matrix of the correspondence between design parameters and remanufacturing process variables. For a linear design, the elements in the design matrix $[A]$ are constants, and the equation (1) is deformed, we can obtain

$$
[E] R P=\left[A^{-1}\right] D P
$$

The equation (2) can be obtained by differentiating the time

$$
[\boldsymbol{E}] \mathrm{d} \boldsymbol{R P}=\left[\boldsymbol{A}^{-\mathbf{1}}\right] \mathrm{d} \boldsymbol{D P}
$$

The $i$-th element in the vector $\mathrm{d} \boldsymbol{D P}$ is written as equation (4)

The equation (4) is deformed, we can obtain

$$
\mathrm{d} R P_{i}=\boldsymbol{A}_{i 1}^{-1} \mathrm{~d} D P_{1}+\boldsymbol{A}_{i 2}^{-1} \mathrm{~d} D P_{2}+\cdots+\boldsymbol{A}_{i n}^{-1} \mathrm{~d} D P_{n}
$$

$$
\mathrm{d} D P_{i}=\frac{1}{\boldsymbol{A}_{i i}^{-1}} \mathrm{~d} R P_{i^{-}} \sum_{\substack{j=1 \\ j \neq 1}}^{n} \frac{\boldsymbol{A}_{i j}^{-1}}{\boldsymbol{A}_{i i}^{-1}} \mathrm{~d} D P_{j}
$$

All manuscripts must be in English, also the table and figure texts, otherwise we cannot publish your paper. Please keep a second copy of your manuscript in your office. When receiving the paper, we assume that the corresponding authors grant us the copyright to use the paper for the book or journal in question. Should authors use tables or figures from other Publications, they must ask the corresponding publishers to grant them the right to publish this material in their paper.

After quantization, the values in the design matrix are dimensionless. In each row of the design matrix, the design parameters corresponding to its diagonal elements are selected as output parameters (and it can be shown that the correct selection of the design parameters is unique for each row [11]). According to the method provided in the literature [12], the design structural matrix $D S M_{R P}$ of heavy machine tools design parameters based on the remanufacturing process can be obtained. $D S M_{R P}$ describes the correlation between design parameters from the perspective of remanufacturing process. The row and column elements in the matrix represent the relevant information values between the design parameters, and in general this matrix is an asymmetric matrix.

\section{The DSM of design parameters correlation for structure}

In addition to the previously described DSM which considered from the regeneration domain, the design parameters of heavy machine tools are not isolated in the structure, there is a certain relationship between each other, It is shown that there is an assembly relationship between one 
component and one or more parts, or no assembly relationship but the relative position between them have more stringent requirements. To sum up, the structural correlation between design parameters are mainly classified into physical correlation and geometrical correlation [13].

The physical relation and geometrical relation between the design parameters of heavy machine tools are analyzed and the evaluation criteria of physical correlation and geometrical correlation of the design parameters are established. According to the correlation criterion, the physical correlation DSM, $D S M_{p h y}$, and the geometrical correlation DSM, DSM geo of heavy machine tools design parameters can be established, then the structural correlation DSM of heavy machine tools design parameters can be obtained from the following equation.

$$
D S M_{s t r}=w_{g e o} D S M_{g e o}+w_{p h y} D S M_{p h y}
$$

Where $w_{\text {phy }}$ and $w_{\text {geo }}$ represent the weight of physical correlation and geometrical correlation respectively, which can be determined according to the AHP method.

The resulting $D S M_{s t r}$ is different from $D S M_{R P}$ in that it is a symmetric design structure matrix. The row and column elements of the matrix are also described as bidirectional relationships, but the values are the same, indicating that the effects of both sides are equal to the specified row and column elements.

\section{Total correlation DSM of design parameters}

$D S M_{R P}$ and $D S M_{s t r}$ express the correlation between the design parameters of heavy machine tools from the perspective of remanufacturing process and structure respectively. In order to obtain the total correlation value, $D S M_{R P}$ needs to be normalized. Assuming that $r_{i j}$ denotes an element in the $D S M_{R P}$, it can be normalized by the following equation

$$
r_{i j}^{\prime}=\frac{r_{i j}-r_{i j}^{\text {min }}}{r_{i j}^{\text {max }}-r_{i j}^{\text {min }}}
$$

In this equation, $r_{i j}^{\max } 、 r_{i j}^{\min }$ denote the largest correlation value and the smallest correlation value in $D S M_{R P}$, respectively.

After normalization, $D S M_{R P}$ becomes $D S M_{R P}^{\prime}$, where the elements are in the range of 0 to 1 . Accordingly, the total correlation matrix of the heavy machine tools design parameters can be obtained by the following equation

$$
D S M_{c o r}=w_{s t r} D S M_{s t r}+w_{R P} D S M_{R P}^{\prime}
$$

Where $w_{s t r}$ and $w_{R P}$ indicate the different weight values of structural correlation and remanufacturing correlation in the total correlation respectively, which can be determined similarly according to the AHP method.

\section{THE ESTABLISHMENT OF DESIGN PARAMETERS REMANUFACTURING PROCESS SIMILARITY DSM}

In the remanufacturing process of heavy machine tools, the process similarity not only makes the distinction between different modules more obvious, but also can reasonably organize the manufacturing process of product module, effectively reduces the process repeatability and manufacturing costs. Therefore, in order to improve the processing efficiency of the heavy machine tool remanufacturing, the internal components should have the same production process as possible, so as to improve the production and processing speed of the module. The remanufacturing process of some components is shown in Table 1 below. 
TABLE 1. The remanufacturing process of some components.

\begin{tabular}{|c|c|}
\hline Component & Remanufacturing process \\
\hline $\begin{array}{c}\text { Bed, Column, Beam, Base, Table, } \\
\text { Case body }\end{array}$ & Disassembly, Cleaning, Detection, Machining \\
\hline Tool post component & $\begin{array}{c}\text { Disassembly, Cleaning, Detection, Machining, } \\
\text { Reassembly }\end{array}$ \\
\hline Spindle, Guide rail & $\begin{array}{c}\text { Disassembly, Cleaning, Detection, Machining, } \\
\text { Surface treatment }\end{array}$ \\
\hline Worm and worm wheel pair, Gear pair & $\begin{array}{c}\text { Disassembly, Cleaning, Detection, Machining, } \\
\text { Surface treatment, Reassembly }\end{array}$ \\
\hline $\begin{array}{c}\text { Standard part, Motor, Chip removal, } \\
\text { Oil mist separator, Machine work } \\
\text { lamp, Inverter, Vertical and horizontal } \\
\text { ball screw pair, Vertical and horizontal } \\
\text { screw bearing and nut, Electric knife, } \\
\text { Lubrication pump, Belt pulley, } \\
\text { Brake and clutch, Other accessories }\end{array}$ & Outsourcing \\
\hline
\end{tabular}

It is assumed that the incidence matrix of the design parameters and the remanufacturing process route of heavy machine tools is $\boldsymbol{P}$, the elements in the matrix are $\mathrm{P}(i, j), i \epsilon I, j \epsilon J$, where $I$ is the design parameter set, $J$ is the remanufacturing process link set. Each element $\mathrm{P}(i, j)$ in the matrix is represented by a Boolean value $\{0,1\}$ indicating whether the remanufacturing process route of heavy machine tools design parameters contains the corresponding process link, so that remanufacturing process route string corresponding to each design parameter can be established.

Through the relationship matrix between the heavy machine tools design parameters and remanufacturing process route string, the similarity design structure matrix $\mathrm{S}(i, j)$ between the different design parameters of the remanufacturing process route can be established, the elements $\mathrm{s}(i, j)$ can be determined by the following equation according to the numerical value of similarity unit method [14]

$$
\mathrm{s}(i, j)=\frac{n}{k+l-n} \sum_{j=1}^{n} \delta_{j} r_{k l j}
$$

Where, $i \epsilon I, j \epsilon J, k$ and $l$ represent the number of process in the remanufacturing process string of the heavy machine tools design parameters $i$ and $j$, respectively, $n$ represents the similar number of processes with two design parameters, $r_{k l j}$ represents the similar characteristic value proportional coefficient of the $j$-th similar process, the value can be between 0 to $1, r_{k l j}$ represents the weight coefficient of the $j$-th similar process, which can be determined by AHP method, and $0 \leq d_{j} \leq 1$, $\sum d_{j}=1$. The same normalization method is used to deal with the similarity DSM.

\section{TOTAL INTERACTION DSM OF DESIGN PARAMETERS AND ITS PARTITION}

\section{Total interaction DSM of heavy machine tools design parameters}

From the above analysis, the correlation DSM of design parameters and similarity DSM of remanufacturing process of heavy machine tools have been obtained. Assuming there are $n$ underlying design parameters, based on the inter-domain hierarchical decomposition of $\mathrm{AD}$, then the correlation DSM and similarity DSM are $n \times n$ matrices.

Considering the modular design of the correlation and similarity of the heavy machine tools design parameters, it is a multi-objective decision-making problem. Multi-objective optimization is often very difficult to achieve at the same time. Most multi-objective decision-making methods use the weighting of different target attributes to analyze the preference value of target attribute synthetically [15]. Gershenson points out that the module is composed of many components with minimal correlation and similarity between the other parts of the module [16]. Therefore, in order to 
obtain a more reasonable analysis result, the aggregation of the two indexes is carried out by the preference aggregation method [15], which is considered to be the same preference attribute of the correlation and similarity.

$$
D S M_{\text {int }}=\left(\frac{w_{\text {cor }} \alpha_{c o r}^{\tau}+w_{\text {sim }} \alpha_{\text {sim }}^{\tau}}{w_{\text {cor }}+w_{\text {sim }}}\right)^{\frac{1}{\tau}}
$$

Where, $D S M_{\text {int }}$ fully reflects the value of interaction relationship between the design parameters. $w_{c o r}$ and $w_{\text {sim }}$ represent different weight values of correlation and similarity, respectively. Without loss of generality, the weight value is assumed to be a positive value and can be normalized. $\tau$ is the standard of compensation level, the greater the value of $\tau$, the greater the preference for one of the attribute indexes. $\alpha_{c o r}$ and $\alpha_{\text {sim }}$ are the correlation and similarity values to be clustered, respectively. The resulting total interaction matrix is shown in Figure 2 below.

\begin{tabular}{|c|c|c|c|c|c|c|c|c|c|c|c|c|c|c|c|c|c|c|c|}
\hline \multicolumn{1}{|c|}{} & \multicolumn{10}{|c|}{ DP } \\
\hline & 1 & 2 & 3 & 4 & 5 & 6 & 7 & 8 & 9 & 10 & 11 & 12 & 13 & 14 & 15 & 16 & $\cdots$ & $\mathrm{n}$ \\
\hline 1 & & $\mathrm{X}$ & & & & & & & & & & & & & & & & \\
\hline 2 & $\mathrm{X}$ & & & & & $\mathrm{X}$ & & & & & & & & & & & & \\
\hline 3 & & & & $\mathrm{X}$ & $\mathrm{X}$ & $\mathrm{X}$ & & & & & & & & & & & & \\
\hline 4 & & & $\mathrm{X}$ & & $\mathrm{X}$ & $\mathrm{X}$ & & & & & $\mathrm{X}$ & & $\mathrm{X}$ & $\mathrm{X}$ & $\mathrm{X}$ & & & \\
\hline 5 & & & $\mathrm{X}$ & $\mathrm{X}$ & & $\mathrm{X}$ & & & & & & & & & & & & \\
\hline 6 & & $\mathrm{X}$ & & $\mathrm{X}$ & $\mathrm{X}$ & & & $\mathrm{X}$ & $\mathrm{X}$ & $\mathrm{X}$ & & & & & & & & \\
\hline 7 & & & & & & & & $\mathrm{X}$ & & & & & & $\mathrm{X}$ & & $\mathrm{X}$ & & \\
\hline 8 & & & & & & $\mathrm{X}$ & $\mathrm{X}$ & & $\mathrm{X}$ & $\mathrm{X}$ & & & & & $\mathrm{X}$ & $\mathrm{X}$ & & \\
\hline 9 & & & & & & & & $\mathrm{X}$ & & $\mathrm{X}$ & & & & & & & & $\mathrm{X}$ \\
\hline 10 & & & & & & & & $\mathrm{X}$ & $\mathrm{X}$ & & & $\mathrm{X}$ & $\mathrm{X}$ & & & & & \\
\hline 11 & & & & $\mathrm{X}$ & & & & & & $\mathrm{X}$ & & & & & $\mathrm{X}$ & & & \\
\hline 12 & & & & $\mathrm{X}$ & & & & $\mathrm{X}$ & & & & & $\mathrm{X}$ & $\mathrm{X}$ & $\mathrm{X}$ & & & \\
\hline 13 & & & & $\mathrm{X}$ & & & $\mathrm{X}$ & & & & & $\mathrm{X}$ & & & $\mathrm{X}$ & $\mathrm{X}$ & & $\mathrm{X}$ \\
\hline 14 & & & & $\mathrm{X}$ & & & & $\mathrm{X}$ & & & & & $\mathrm{X}$ & & & & & \\
\hline 15 & & & & $\mathrm{X}$ & & & $\mathrm{X}$ & & & & & $\mathrm{X}$ & & & & & & $\mathrm{X}$ \\
\hline 16 & & & & & & & $\mathrm{X}$ & & & & $\mathrm{X}$ & & & & & & & \\
\hline$\cdots$ & & & & & & & & & & & & & & & & & & \\
\hline $\mathrm{n}$ & & & & & & & & $\mathrm{X}$ & $\mathrm{X}$ & & & $\mathrm{X}$ & & & $\mathrm{X}$ & & & \\
\hline
\end{tabular}

FIGURE 2. Total interaction matrix of heavy machine tools design parameters.

\section{Module partition of heavy machine tools based on PSO-MDL algorithm}

Module identification is a complex optimization process with many influential factors, which can be optimized by modern optimization method combined with appropriate objective function. In this paper, DSM is clustered by PSO algorithm based on MDL to realize reasonable module partition. Through the cooperation and competition among the particles in the swarm, PSO generates all the intelligent guidance to optimize the search, the largest feature of the algorithm is the ability to achieve simple and stronger global optimization. The basic idea of the MDL is to establish a mathematical model that can accurately describe the object and to achieve the best compromise between low description complexity and model accuracy.

\section{CONCLUSION}

In this paper, a module partition methodology of heavy duty machine tools for green manufacturing is proposed. Based on the method of total differentiation, the design matrix in AD is transformed into DSM, and the design process of heavy machine tools is extended to customer 
domain, functional domain and structural domain, process domain and regeneration domain. The correlation and similarity of the heavy machine tools design parameters in structural domain and regeneration domain are analyzed, and focuses on the analysis of the correlation and similarity of the design parameters based on the remanufacturing process in regeneration domain. The design matrix of correlation and similarity is established, and then The design matrix is transformed into DSM that takes into account the design parameters from different domains. The PSO algorithm based on MDL is used to realize the reasonable partition and recognition of the module.

\section{ACKNOWLEDGMENTS}

The research presented in this paper was supported by National Natural Science Foundation of China (51575010), Beijing Nova Program (Z1511000003150138), the Leading Talent Project of Guangdong Province, Open Project of State Key Lab of Digital Manufacturing Equipment and Technology (Huazhong University of Science and Technology), Shantou Light Industry Equipment Research Institute (2013B090900008), and Natural Sciences and Engineering Research Council (NSERC) of Canada (185788).

\section{REFERENCES}

[1].X. Binshi, Development status and prospect of green remanufacturing engineering, J. Engineering Sciences. 1(2011).

[2].H. Cao, Y. Du, F. Liu, Customised design of remanufactured products and optimisation model for cores reuse, J. International Journal of Computer Integrated Manufacturing. 25(2012) 741749.

[3].Y. Du, H. Cao, F. Liu, An integrated method for evaluating the remanufacturability of used machine tool, J. Journal of Cleaner Production. 20(2012) 82-91.

[4].Y. Liu, S.K. Ong, A.Y.C. Nee, Modular Design of Machine Tools to Facilitate Design for Disassembly and Remanufacturing, J. Procedia CIRP. 15(2014) 443-448.

[5].Z. Sheng, Y. Li, L. Wu, Lifecycle-oriented product modular design of CNC machine tools, J. Proceedings of the Institution of Mechanical Engineers, Part C: Journal of Mechanical Engineering Science. 0954406215625679(2015).

[6].N.P. Suh, Axiomatic Design: Advances and Applications, J. (2001).

[7].D.V. Steward, The design structure systems: A method for managing the design of complex systems, J. IEEE Transactions on Engineering Management. 28(1981)71-74

[8].R. Poli, J. Kennedy, T. Blackwell, Particle swarm optimization, J. Swarm intelligence. 1(2007)33-57.

[9].J. Rissanen, Hypothesis selection and testing by the MDL principle, J. The Comput Journal. 42(1999) 260-269.

[10]. T.L. Saaty, How to make a decision: the analytic hierarchy process, J. European journal of operational research. 48(1990) 9-26.

[11]. Q. Dong, D.E. Whitney, Designing a requirement driven product development process, J. (2001)1-11.

[12]. Q. Cheng, G. Zhang, P. Li, Identification of key coupled design parameters in axiomatic design, J. Journal of Mechanical Engineering. 45(2009).

[13]. S. Pan, F. Gao, P. Feng, Module partition method research under the circumstances about mass customization, J. Chinese Journal of Mechanical Engineering. 39(2003)1-6.

[14]. Z. Meili, Principles of similarity formation between similar systems, J. International Journal 
of General System. 27(1999)495-504.

[15]. M.J. Scott, Formalizing negotiation in engineering design, D. California Institute of Technology. (1998) .

[16]. J.K. Gershenson, G.J. Prasad, S. Allamneni, Modular Product Design: A Life-Cycle View, J. Society for Design and Process Science. 3(1999)13-26. 